\title{
IRS POST-FILING PROCESSES SIMULATION MODELING: A COMPARISON OF DES WITH ECONOMETRIC MICROSIMULATION IN TAX ADMINISTRATION
}

\author{
Arnold Greenland \\ Erica Layne Morrison \\ IBM Corporation \\ 6710 Rockledge Drive \\ Bethesda, MD 20817, U.S.A.
}

\author{
David Connors \\ TranSystems \\ 500 Church St, Suite 480 \\ Nashville, TN 37219, U.S.A.
}

\author{
John L. Guyton \\ Michael Sebastiani \\ Internal Revenue Service \\ 500 North Capitol St. NW \\ Washington, DC 20001, U.S.A.
}

\begin{abstract}
IRS Office of Research Headquarters measures and models taxpayer burden, defined as expenditures of time and money by taxpayers to comply with the federal tax system. In this research activity, IRS created two microsimulation models using econometric techniques to enable the Service to produce annual estimates of taxpayer compliance burden for individual and small business populations. Additionally, a Discrete Event Simulation (DES) model was developed to represent taxpayer activities and IRS administration in post-filing processes. This paper discusses the development of the DES Post-filing Model and compares microsimulation and DES approaches from the perspectives of policy measurement, flexibility and reporting by IRS analysts. The main strengths of microsimulation are robust segmentation of results and the ability to support representation of imbedded, joint distributions in a complex, structural model. The strengths of using DES are its queuing capability and increased flexibility to update the granularity of both the data and process changes.
\end{abstract}

\section{INTRODUCTION}

The IRS has long-standing interest in serving taxpayers through efficient tax administration, reducing taxpayer burden consistent with its enforcement responsibilities. Taxpayer burden, in this case, is defined as time and money expenditures by taxpayers complying with federal income tax requirements. Our definition includes such pre-filing activities as recordkeeping that would not be incurred without a federal tax system and excludes psychological costs and deadweight losses from economic behavioral changes (Guyton et al., 2003). Simulation models described in this paper were developed to meet several primary objectives. First, IRS sought to create a forecasting method that would allow the Service to esti- mate the total burden in any particular tax year in response to requirements under the Paperwork Reduction Act (PRA). Second, the Service required a decision support system contributing to policy and tax administration decisions, relating to changes in tax law and regulation in light of the impacts on burden. Policy makers in the Department of Treasury had, for many years, examined the impact on the total tax liabilities of taxpayers for such tax changes, but they had not regularly understood the impacts on taxpayer time and burden-related expenditures of those decisions. Finally, the IRS sought to report an overall burden estimate to Congress and the public, accomplished through a random sample survey of over 14,000 taxpayers.

Out of the initial research, the IRS created two models using microsimulation, an approach widely used to investigate the impact of public policies by examining behavior of individuals or entities at the micro-level (c.f. Gupta and O'Hare, 2000). Microsimulation models operate by accessing administrative records of the entities of interest (in this case tax returns), in many cases using a probability sample, and applying mathematical algorithms to simulate various behaviors and outcomes. By changing the parameters of these algorithms, policymakers can simulate a change in tax law or regulation and observe the resulting change in outcomes. Because such models run on micro-level data, impacts can be measured both in the aggregate and for various subgroups of entities. The two models created use IRS tax administration data as inputs into an econometric model to estimate baseline burden amounts. The econometric models were fit using the administrative data combined with data from several major taxpayer surveys in which taxpayers were asked about tax-related activities and the costs incurred.

Subsequent to the research of taxpayer burden in the pre-filing and filing processes, the IRS decided to study time and money expenditures incurred by taxpayers after submission of their returns, i.e., the taxpayer post-filing process. The focus widened in this stage of research to 
more explicitly represent IRS internal processes, since these activities are key drivers of taxpayer post-filing activity. Once the need to represent detailed internal processes was recognized, it was decided to further broaden the scope of the model to consider IRS costs as well. Enforcement activities constitute the largest portion of the Service's budget; in federal fiscal year 2006, the IRS audited 1,293,681 returns, issued 3,742,276 levies, and served 629,813 liens (IRS Databook, 2006). Clearly, understanding the impact on both taxpayers and the Service held powerful practical appeal, as well as theoretical interest, not least of which were expected interdependence and substitution effects with pre-filing and filing burden. The authors of this paper proposed altering the modeling approach from the use of microsimulation to the use of discrete event simulation (DES) in order to better support analysis of key aspects of the post-filing process.

In the sections below, we describe the modeling approach for the DES model, compare the DES and microsimulation approaches, discuss the relative benefits of the two methods and describe further potential for the DES approach at IRS.

\section{MODELING APPROACH}

The DES model represented a significant departure from the earlier econometric models in use for the pre-filing and filing processes. This DES approach has many benefits. Primary among them are the ability to capture dynamic processes, ease of software configurability, improved scalability, and ease of successive data refinement. Other advantages are the ability to support estimation of various performance metrics, including time and dollars expended in complex, circuitous compliance processes.

Characteristics of the post-filing environment required the ability to capture complex, interrelated processes with significant queuing impacts. Additionally, as we will discuss below, the availability of data to support econometric estimation of resources required by various low-level processes from high level burden data was not likely. A more flexible foundation for future refinement was required.

\subsection{Environment and Input Modeling}

Post-filing processes constitute a more complex environment than pre-filing and filing activities, which are modeled with reasonable accuracy as simple, isolated, onedirectional processes. In contrast, post-filing processes comprise virtually innumerable labyrinthine pathways through four main segments: clarification, examination, appeal and collection. The Internal Revenue Manual (IRM) documents IRS policy (such as the statutory time allowed for taxpayers to request appeal) and praxis (such as the elapsed time allocated for paperwork to go through the mail). A taxpayer case can often span years, opening multiple issues ('modules') with loops, queues and process sequences. Scarce resources and mandated workload and 'inventory' levels constitute a major constraint to the Service's enforcement efforts. Potentially collectible taxpayer cases may be kept in a queue system until the statute of limitations expires.

For IRS, the vision for model development included successive refinement over time, inspiring a milestone based approach. Incremental development was supported in two ways: one, the model was developed rapidly with basic functionality; two, the flexible framework enabled users to configure the model directly with new data and processes. Expanded functionality could be added to the model as resources permitted.

A further requirement driving the DES decision was the need for sequential, iterative refinement of input data. In microsimulation, tax return sample and microdata from a given filing year are released once or twice in microfile format. This enables the estimation of econometric relationships using a foundational file, with aging adjustments. In contrast, post-filing data is constantly arriving and being processed, coming from numerous sources. Short of building a data architecture solution, the data would have to be added to the model in successive waves and refreshed at different schedules.

The team began modeling the tax administration environment with a process flow model of the post-filing activities using the IDEF0 modeling framework (FIPS PUBS 183, 1993). The IDEF0 model follows taxpayers from introduction into the post-filing process through post-filing activities based on user-defined specifications.

IDEF methodology was initially developed by the US Air Force to model business processes in their operations, such as maintenance. It has been accepted as one of the most structured and clearly understandable methods for communicating the details of a business process. To address some of the limitations of IDEF in conceptual modeling, such as the inability to specify resources and represent user perspectives (c.f. Heavey and Ryan, 2006), For Exposition Only (FEO) and swimlane models augmented the IDEF model. An example of an IDEF model created under this project is shown in Figure 1. 


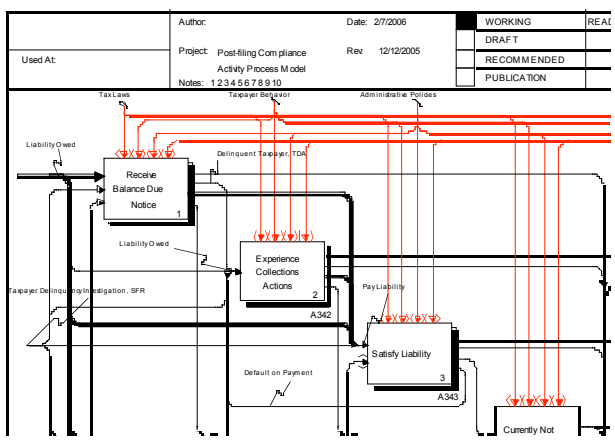

Figure 1: IDEF Process Flow Example

The goal of the IDEF modeling was to define the modeling space, determine the right level of aggregation for modeling, and document the data and resource requirements used in the process. Using the IDEF model as a basis and form of model documentation, the team made a transition to a DES modeling environment.

\subsection{Post-filing Model Development}

The Post-filing Model was developed using a layered approach. One requirement was the ability to be scaled based on the inputs and to represent all or portions of the post-filing process at various levels of detail. As model users needed greater detail, they would be able drill down further into the process to create and understand more and more detail of the process.

The decision support system 'Modeling Studio' is constructed using three technologies. The interface and all input and output routines are developed in Visual Basic .NET. The simulation model is developed in AnyLogic. Both languages support object-oriented programming, which will help reduce the complexity and duration of future enhancements. Microsoft Access is used to query and store data for a single scenario.

The Post-filing Model includes scalable input tax return generation. Through flexible case selection, the user can define the cases and characteristics at multiple levels. These include 'types' of taxpayers (Wage and Investment, Self-Employed), 'categories' of returns filed, attributes of interest (such as prior collection history), the volume of cases with the likelihood and frequency of filing a specific return type, and the arrival frequency of returns throughout the time cycle. The user can expand or reduce the number of returns to model future predictions and run scenarios for a subset of cases in the system, later integrating with a full system analysis.

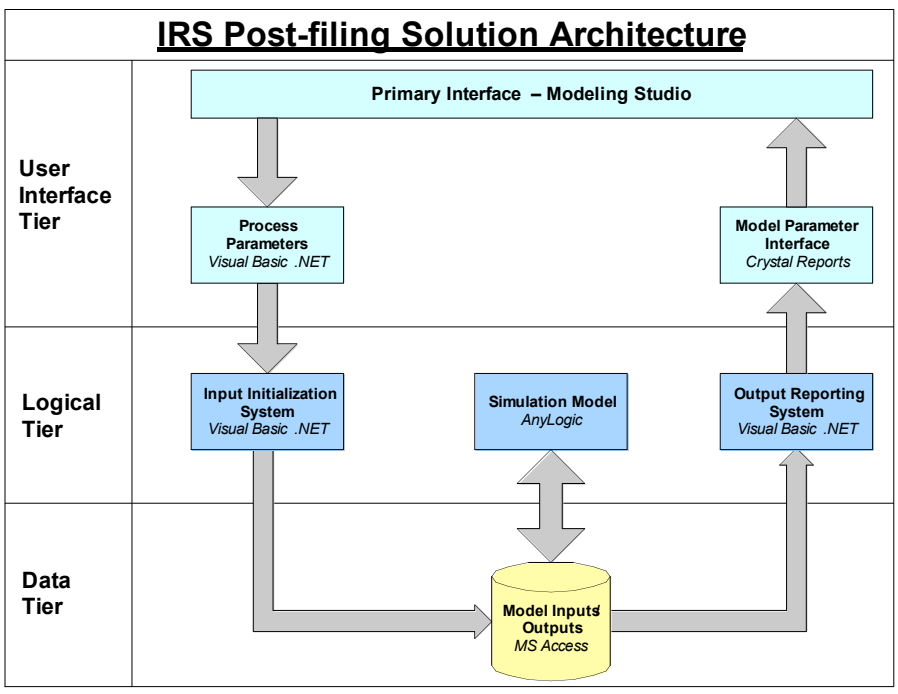

Figure 2: DES Architecture

Process parameters are collected as cases traverse the processes. These are cycle time (total time that taxpayers are in the system), the taxpayer time burden (specific amounts of time spent on compliance activities while in the system), and taxpayer cost burden.

Phase I of the model was delivered to IRS Research in Spring 2006. In the following year, verification was undertaken through unit and stress tests, together with validation through a number of scenarios with policy analysts and senior managers in operating divisions (While initial validation was performed with IRS Research, more extensive validation in the Collection and Appeals functions is in progress as of this writing).

\section{COMPARISON OF MICROSIMULATION AND DES APPROACHES}

Having built three comparable models within one policy area, we analyze strengths and weaknesses of these two 'micro' modeling approaches in the policy framework. Since practicality and resource availability prevented duplication of either model in the alternative framework, the insights presented here are based on experience with the two modeling frameworks rather than controlled statistical analysis.

Relative to macro-level models, microsimulation and DES both share a common transparency since they are built from the 'micro' record level up; each record or observation can be traced back from the aggregate reported level. 


\subsection{Comparison of DES to the Microsimulation Approach}

Taxpayer recordkeeping, tax planning, and form completion activities are closely tied to income, expense, deduction, credit, and payment characteristics. It was, therefore, natural to start with a microsimulation tax model as a foundation for the pre-filing and filing processes.

The taxpayer burden model was not a standard microsimulation because of the interplay between the microsimulation aspects and the econometric modeling aspects of the model. Usually, the input file in a microsimulation model is developed from administrative records. A classic example of such a file would be loans in a loan portfolio. It might be difficult to use statistical methods to represent the diversity and complexity of such loans and the associations between the loans (e.g., geographic correlations) without using administrative data. In the application to taxpayer burden, we faced the challenge that the actual burden amounts had to be determined through a separate survey data acquisition process and matched to the corresponding tax return data.

The microsimulation approach worked quite well for modeling liability because all of the data used in that model was obtained from administrative records, and these records were updated annually. The key difference between the burden models and most microsimulation models was our incorporation of econometric techniques to structure relationships. Our statistical foundation in the taxpayer burden models was founded in an initial taxpayer survey of over 14,000 taxpayer interviews- data which cannot be recreated without considerable investment. At the beginning of the modeling process, the structural relationships among burden drivers was relatively unexplored; preserving these embedded, complex relationships on the input data was advantageous.

However, since the dynamical relationships and time and money drivers were fundamentally imbedded in the data, foundational econometric relationships, if not reestimated, limited our ability to incorporate new taxpayer behavior. In the area of tax administration, the last decade has witnessed dramatic rises in paid and software preparation, as well as changes in tax forms and process changes. Re-estimation of models of taxpayer behavior with respect to preparation and filing methods identifiable through the administrative data have been possible, but gains from re-estimating basic burden model relationships is limited until such time as new burden data are collected and revised relationships estimated. While some interim adjustments reasonably extend model capabilities, they are essentially augmentations to the basic econometric microsimulation approach.

\subsection{Strengths of DES Approach to Post-filing}

In comparison, DES provided a more flexible and robust approach to changes in data and model specification, particularly germane to the post-filing administration landscape. Model structure can be easily adjusted in the configurability of the decision support system and the specification of the scenario.

First, core model capability can be configured in a standard simulation package - in this case, AnyLogic. This strength for DES was emphasized as important though our experience using the microsimulation models for prior applications to study new requirements for tax reporting. One such example was the decision to provide taxpayer relief by lessening requirements to keep certain records. Taxpayer burden survey data was collected from taxpayers under the former tax policy requirement for recordkeeping; so any burdens reported had the prior reporting mechanism imbedded in the data, and it could not be "extracted" statistically. If the activity itself is modeled, it is much easier to "extract" the steps that relate to the change under consideration. If the details were not modeled in an initial model, the hierarchical nature of DES models can be used to create a lower level modeling adjustment for use in comparing the alternative reporting activities.

Second, the data that drives the models are accessible to the model users through the user interface. Changes in dynamics based on micro-level transactional data (times to complete specific activities and numbers of resources required to do so) can be estimated independently from a large data acquisition process.

Table 1: Comparison and Contract of Microsimulation and DES Approaches

Econometric Microsimulation

Strong individual level effects

Enhanced by econometric linkage, microsimulation preserves imbedded relationships

Low flexibility when econometric coefficients change due to process and policy changes

Enhanced with a rich administrative input file.

\section{DES}

Represents overall system effects, such as queues.

Ability to gather new information on sub-processes.

Ability to progressively elaborate and refine data and distributions.

This capability and flexibility can become a liability if not carefully managed. Unlike microsimulation, where relationships and time and money drivers remained imbedded in the data, the DES separated many of these 
data out, exposing them to the user, allowing changes to be made quite easily. However, if the data supporting these changes are not obtained in a controlled process, the quality of estimates can be questioned. Therefore, it is critically important to create processes for making changes in the key burden driving data, such as the data elements mentioned above, so that they are based on actual data collection, or, at least, documented clearly as to their source.

A third major benefit of the DES approach, that was not included as a requirement but simply emerged during the application, is the relationship between the process model for taxpayers performing their compliance activities and the modeling of the parallel activities performed by the IRS. Simply put, the DES models that are used to estimate time and expenses of taxpayers can easily be expanded to estimate time, staffing, resource requirements, and expenses associated with the IRS staff managing the compliance process. This was particularly apparent in the post-filing model because so much of the IRS staff compliance time is dedicated to that part of the compliance process. While IRS is just beginning to pursue expanding the model to make estimates on the IRS side, DES has significant potential to provide decision-making insight across multiple objectives and multiple attributes.

\subsection{Perspective Shifts from DES Approach}

As we suggested earlier, the Post-filing DES Model represented a significant shift in the compliance burden modeling approach within the IRS Office of Research, many of whom are senior economists and statisticians more familiar with econometric methods. As discussed above, DES allows the modeler great access to the details of the dynamical relationships and activities that make up the total burden, while the econometric aspects of the model imbedded many of those dynamics in the coefficients of the estimation models themselves. The benefit of the DES approach is that the specific elements that drive the model, for example the time to perform a specific recordkeeping activity, is a value that is easily understood. Changes to such a data item, even if based on judgment alone, can be justified and communicated to a wide audience of reviewers, so that a specific proposed change in that activity can be studied.

The task, then, is to provide users of the new DES model with the appropriate knowledge of how this model works and how one can make changes to it to achieve their modeling objectives. In many cases, the adjustments can be made based on solid data. An example might be changing a threshold for the need to itemize deductions. This situation might be reflected in the DES model as the number of entities that experience a particular path in the model. One can use administrative records to determine volumes of taxpayers that might be affected such a change, and change the flow of entities in the model - resulting in the new burden estimates.

A second approach to adjusting data is to do a limited scope survey. For example, suppose there is a proposed change in a specific tax compliance activity that was estimated in the initial model as using, say, an average of one hour (with an associated standard deviation of time). One can select a small number of individuals who perform this activity and determine the impact, maybe as a fraction of original time, to perform the new activity.

Finally, when it is impossible to use either administrative data or limited-scope surveys, this method allows the use of expert judgment to estimate changes in key modeling data parameters. When using this approach, it is important to employ the most reliable tools for obtained expert judgment, for example, the use of the Delphi Methods, or other well-known methods for obtaining such information. The sources of such data must be scrupulously documented and open to review by those who must use and interpret the results.

Using the DES approach in taxpayer compliance studies was a 'paradigm shift' in multiple ways. One of the most surprising was how the choice of modeling approach influenced the way we conceptualized 'real world' compliance costs. In the microsimulation models, the implicit or explicit assumption of model stakeholders was that the taxpayer burden above and beyond legitimate tax liability ought to be minimized. The DES approach facilitated the treatment of burden as an active input into the compliance pathways chosen, with behavioral ramifications confirmed through in-depth qualitative interviews with taxpayer 'participants.' Modeling compliance cost as a dynamic administrative parameter allowed us more freedom, both within the model and subsequently in our conceptualization of the real world policy problem. This generated interesting insights, such as the realization that higher compliance processes earlier in the process may shorten overall compliance costs, while compliance costs generally have a parametric impact in pre-filing and filing behaviors.

\section{FUTURE OPPORTUNITIES}

Given the post-filing model's ability to represent a userdefined process and generate taxpayer and return volumes, the model provides a flexible foundation for future enhancements. One of the best opportunities involves expanding IRS constraints to the process definition. The model could be enhanced to represent IRS staff groups and their associated capacities with very little modification to the current logic. Resource representation transforms the model from a taxpayer burden model to a scalable, process improvement tool that is customized to the IRS's unique needs. 
Moving beyond IRS resource representation, the model could also be enhanced to represent return management logic based on resource availability, case attributes, and current process dynamics. Taxpayers and returns could be routed through the processes based on user-defined decision sequences and prioritization rules. With this functionality, the IRS could test the impact of alternate case management and decision strategies.

Each year the IRS receives a large volume of returns from taxpayers. The returns are analyzed and classified based on their characteristics. The IRS then selects the returns to investigate based on those classifications. The question facing the IRS is what returns should they select in order to maximize compliance and revenue. The model could be extended to represent the process by which the IRS selects a subset of returns to work on based on their classifications. Case selection inputs could be added that would allow the user to define what mix of returns should be selected and processed by the model. The result of the return mix could yield revenue outputs based on historical results for similarly classified returns.

The microsimulation models continue to provide a parsimonious modeling approach to pre-filing and filing burden, meeting the objectives of high level reporting and detailed segmentation analysis. However, the DES approach was required for flexibility, queuing capacity and low-level process change in the post-filing application. Integrating estimates from these two approaches is the ultimate direction for IRS to provide comprehensive estimates and explore the relationships between pre- and post-filing taxpayer behavior. To refine Post-filing Model responsiveness, econometric analysis (elasticities from tax literature) could be incorporated within the DES model. Multi-agent based simulation (MABS) models may prove complementary as well through providing parameters for taxpayer behavior, such as the expected increase in voluntary compliance from increased audits (Bloomquist, 2004).

\section{CONCLUSION}

The comments and examples above demonstrate the value from using DES for the estimation of taxpayer compliance costs in post-filing processes. The main improvements in using DES for post-filing are increased flexibility for micro-level data and process changes and queuing capacity. Second, this approach allows for expansion into other areas of the IRS operations, for example to estimate costs and staffing requirements for staff overseeing the compliance process. Finally, because the reliance on large surveys of taxpayers is lessened substantially, this approach may provide cost benefits which accrue to both the managers of the IRS (because resources can be spent in other ways) and to taxpayers themselves.
In comparison, the pre-filing and filing models have provided benefits using an econometrically-based microsimulation approach. This is particularly instrumental in preserving the relationships among complex input variables and providing overall aggregate reports of taxpayer burden.

\section{ACKNOWLEDGEMENTS}

The authors acknowledge with gratitude Peter Arena, David Brann, Michael Chesman, Donald DeLuca, Barry Dennis, Ben Fuqua, Robert Gillette, Janice Hedemann, Janet Holzblatt, Audrey Kindlon, Emily Knickerbocker, Adam Korobow, Wu-Lang Lee, Allen Lerman, Jay Liao, Mark Mazur, Sarah Myers, Susan Nelson, John O'Hare, Mary Phillips, Eric Reinauer, Michael Stavrianos, Scott Stilmar, Eric Toder, Sarah Tuohy, and Michael Udell for their contributions to the successful implementation of the microsimulation and DES models discussed.

\section{REFERENCES}

Bloomquist Kim M. Multi-agent based simulation of the deterrent effects of taxpayer audits. Presented at the 97th Annual Conference of the National Tax Association. Minneapolis, MN, November 2004.

Federal Information Processing Standards Publications (FIPS PUBS) 183: Integration Definition for Function Modeling (IDEF0), December 21, 1993.

Gupta, A. and O'Hare J. Practical Microsimulation Models. In Contributions to Economic Analysis: Microsimulation Modeling in Government, NorthHolland, 2000.

Guyton, John L., John F. O’Hare, Michael P. Stavrianos, and Eric J. Toder. Estimating the Compliance Cost of the U.S. Individual Income Tax. National Tax Journal, September 2003,673-688.

Heavey, Cathal and John Ryan. Process Modelling Support for the Conceptual Modelling Phase of a Simulation Project. Proceedings of the 2006 Winter Simulation Conference.Eds. L. F. Perrone, F. P. Wieland, J. Liu, B. G. Lawson, D. M. Nicol, and R. M. Fujimoto, 2006.http://www.informssim.org/wsc06papers/100.pdf

Internal Revenue Service. Fiscal Year 2006 Enforcement and Service Results. November 20, 2006. http://www.irs.gov/pub/newsroom/1106_enforcement _stats.pdf.

\section{AUTHOR BIOGRAPHIES}

ARNOLD GREENLAND is an IBM Distinguished Engineer and Executive within the Public Sector Supply Chain Practice. He has over 30 years experience in delivering modeling and simulation services for both public- 
and private-sector clients. His experience includes both project management and technical leadership in the areas of operations research, business process modeling and simulation, business forecasting, network optimization, and systems development. Dr. Greenland serves as IBM representative on the INFORMS Industry Roundtable, a group of industry leaders that advise the Operations Research profession on topics related to practice. Prior to joining IBM Dr. Greenland taught Operations Research at George Mason University, worked as a consultant in several corporations, and was a principal in a successful public sector consulting firm. He received his doctorate in Mathematics from the University of Rochester and a Bachelors of Science degree with High Honors from Case Western Reserve University.

ERICA LAYNE MORRISON is a Managing Consultant in IBM's Public Sector Supply Chain Practice. She holds a Masters Degree in Public Policy and Management from Carnegie Mellon University. Ms. Morrison is passionate about promoting best analytic practices within the public sector; with this goal, she has coauthored articles on spreadsheet error management in academic and practitioner journals.

DAVID CONNORS is a Senior Analyst for TranSystems. His responsibilities include project management, business development, solution design, and development. Mr. Connors started working as a simulation analyst in 2000 after graduating from the Georgia Institute of Technology with a degree in Industrial and System Engineering. He has significant project experience in supply chain analysis, manufacturing, distribution, postal/sorting operations, and health care. Mr. Connors works with simulation tools such as AutoMod, Siman/Arena, Anylogic, and Simflex, as well as programming languages such as Visual Basic, Java, and SQL.

JOHN GUYTON is a Senior Manager in the IRS National Headquarters Office of Research. He leads IRS research efforts in process improvement simulation, demand forecasting, and statistical analysis. Prior to joining IRS, he was a managing consultant in IBM's Operations Analytics service area in their Public Sector Supply Chain Management practice and a manager in the National Economic Consulting group within the national headquarters of PricewaterhouseCoopers' Tax \& Legal Services practice. Dr. Guyton has twelve years experience designing, building, running, maintaining and managing a variety of federal tax simulation models across these three positions. Dr. Guyton has a PhD in Government \& Politics from the University of Maryland with concentrations in game theory, public economics, and analytic methods. He also has a BS in Mathematics from the University of Oklahoma.
MICHAEL SEBASTIANI is an Operations Research Analyst in the Internal Revenue Service's Office of Research. He has been with the IRS for 19 years, and with the Research function for the last 9 years, with a focus on achieving organizational alignment, development of performance measures, and process improvement. Michael holds a B.S. degree in Industrial Engineering and Operations Research from Virginia Tech. 